\title{
Results of Implementing Communicative Language Teaching Method in English Language Learning in 9-Year Elementary Schools. (Albanian Context)
}

\author{
Evis Kapurani \\ European University of Tirana, Doctoral School, Profile Pedagogy, Tirana, Albania \\ eviskapurani@yahoo.com
}

\begin{abstract}
Theoretically Communicative Language Teaching Method (CLT) claims to be one of the best available foreign language teaching methods in teaching and learning foreign language in communication because it improves effectively not only communicative competence of students but also their language acquisition and its use in Albanian schools is an innovation. The purpose of this study is to analyze the results that the use of a contemporary interactive studentcentered method has when it is used in learning a foreign language compared with traditional methods. This is an empirical study which includes control groups where traditional methods are used and experimental groups where CLT method is used based on a comparison between these methods for a period of 6 months. It is mainly focused on the implementation of CLT in Albanian 9-year elementary schools in learning English as a foreign language through communication and interaction compared with other traditional methods used. The study analyzes the impact, results and advantages of the use in practice of CLT method in Albanian 9-year elementary schools on sixth, seventh, eighth and ninth grades, its efficacy in learning, in foreign language acquisition and students performance in four language skills. It contains an analysis of theory versus practice use of CLT as a foreign language teaching method. The data about the implementation of CLT method in practice are collected from teachers and students in Albanian 9-year elementary schools through classroom observation and tests. Classroom observations are focused on finding how the teacher develops the lessons and if it is based on CLT principles on experimental groups and how students react during the lesson in comparison with control groups. Tests are used to compare students' results on learning based on their grades in both groups. All results are converted into percentages. Findings are analyzed based on theoretical issues. The results show that using CLT is a successful method in both learning and teaching compared with other traditional methods.
\end{abstract}

Keywords: Foreign Language Teaching and Learning, Interactive Student-Centered Methods, Communicative Language Teaching Method, Traditional Methods, Effectiveness, Comparison

\section{Introduction}

In different countries nowadays foreign language teaching is done using contemporary interactive student-center methods. It allows students to participate in a variety of activities, often in pairs or small groups, where they can learn from each other and can also discuss and share their ideas. The role of the teacher when the student is at the center is very important, he is a partner in communication and class interaction, reduces the level of stress and workload during the activities by teaching them to help each other in tasks, gives advice for activities that will develop, promotes student-student interaction, recognizes student feedback, enables the student to be free to ask questions, exercises students for an independent assessment of their achievements in the activities. Knowledge of teaching methods makes the teacher aware of different teaching strategies related to learning objectives. Well planned teaching and motivation may reduce classroom management problems, preservation and creation of a comfortable climate in the classroom leads to effective learning. Care that needs to be done to motivate students in learning is an essential feature of teaching skills. Motivation is everything that drives people to do what they want. Strategies and methods that rely on student motivation contain selected topics that are of interest to the students, especially if they are related to students' own experience. The use of contemporary interactive student-center methods with their specific principles and techniques bring to an effective learning. 
The purpose of this study is to demonstrate the theory in practice, that the use of a contemporary student-center method in foreign language teaching is more effective compared to traditional methods. Because it is learnt not only grammar or vocabulary but also communication in a foreign language, accuracy and fluency, it has an impact on the socialization and motivation of the students, the role of teachers in the classroom, in the relationship teacher-student and student-student and therefore teaching, learning and students performance in four language skills improve. This study aims to highlight that the more involved the student, the greater will be the result in learning. Interactive teaching methods such as Communicative Language Teaching (CLT) are very important they motivate the students to learn more to achieve effective learning. Learning in collaboration enhances students' social skills, improves interpersonal relationships, creates models of social behavior and engages students in the learning process and aims to improve critical thinking skills.

\section{Literature Review}

\section{Foreign Language Teaching}

Throughout the history of language teaching methods, linguists have been focused on changes based on learners need in learning a foreign language focusing on oral proficiency rather than on overall language comprehension. Before the $19^{\text {th }}$ century language teaching methods used textbooks which consisted of grammar rules, vocabulary and translation. Grammatical system of the language was on focus and not the real use of language on communication and speaking. Innovations in foreign language teaching began in the 19th century and became common in the 20th century. This led to a large number of different methods, trying to be an improvement of previous ones. Old methods such as Grammar Translation Method or Audio-lingual Method were rejected because of the new methods and approaches introduced as the only solution and problem solving failure in foreign language learning. Richards, Rodgers (2001).

\section{Communicative Competence}

Some methodologists have argued that the communicative competence cannot be reached in a formal instruction. Harmer (1983), for example, argued that a more realistic aim for the classroom was "communicative efficiency". Activities such as information-gap tasks, games, role-plays, and interviews, are usually done orally. In the accuracy/fluency polarity of Brumfit (1984), such activities are usually employed for the development of fluency. Success is measured by how accurately information has been conveyed, or how well a problem has been solved. Communicative language teaching relies heavily on activities that convey information and meaning. Communicative efficiency, or how much and how accurately a message has been conveyed, is often used for evaluating performance on a communicative task.

\section{The Grammar-Translation Method}

Richards, Rodgers (1986) refer to the Grammar Translation Method (GTM) as a traditional method; it was widely used in Europe and foreign language teaching from the 1840s to the 1940s. But its overuse time after time developed the opposition to this method by European linguists in several European countries. This opposition was called the Reform Movement which was the fundamental way for the continuing development of new ways of teaching languages and it raised much opposition which continues even nowadays. There were a lot of factors that brought to the controversy reactions and rejection of the Grammar-Translation Method. The increasing opportunities for communication among Europeans were faced on a demand for communication proficiency and fluency in foreign languages. Educators and linguists become aware about the need for communication proficiency rather than reading comprehension, grammar rules, translation or literary appreciation as the goal for foreign language programs.

\section{The Audio lingual Method}

Richards, Rodgers (1986) stated that the theory of language in which the traditional method Audio lingual Method (ALM) was developed was proposed by American linguists in the 1950s - which came to be known as structural linguistics. Structural linguistics had developed in part as a reaction to traditional grammar. Language was viewed as a system of structurally related elements for the encoding of meaning, the elements being phonemes, morphemes, words, structures, and sentence types. On the one hand, the theoretical foundations of Audiolingualism were attacked as being unsound both in terms of language theory and learning theory. On the other, practitioners found that the practical results fell short of expectations. Students were often found to be unable to transfer skills acquired through Audiolingualism to real 
communication outside the classroom, and many found the experience of studying through audio lingual procedures to be boring and unsatisfying.

\section{Communicative Language Teaching}

The origins of Communicative Language Teaching (CLT) date from the late 1960s when British applied linguists focused to communicative competence in language learning rather than on structured rules. This movement may be considered as a British innovation, but both American and British linguists were involved on this reformation. Richards, Rodgers (1986). The aim of CLT is to make students to communicate in a foreign language using activities such as oral communication activities, communicating with games, problem solving, paintings discussion, story construction, stimulation, role plays, fill in the space exercises, written communication activities, exchanges of letters and messages, dialogue complementation, images, questions etc. Games are a good incentive for motivation and communication which helps in learning a foreign language. The teacher in the classroom aids communication creates situations during activities act as advisory for the students. Because the role of teachers is less dominant than in the other methods the students are at the center. Emphasis is placed on communication processes, instead of language grammar or vocabulary. A variety of materials are used to support the communicative method to language learning. The materials used for this method are seen as a way to influence the quality of interaction in the classroom and in the use of language in communication. Hymes's (1972) theory of communicative competence was a definition of what a speaker needs to know in order to be communicatively competent in a speech community. In Hymes's view, a person who acquires communicative competence acquires both knowledge and ability for language use with respect to:

Whether (and to what degree) something is formally possible;

Whether (and to what degree) something is feasible in virtue of the means of implementation available;

Whether (and to what degree) something is appropriate, adequate, happy, successful) in relation to a context in which it is used and evaluated;

Whether (and to what degree) something is in fact done, actually performed, and what its doing entails.

\section{Methodology and Data Collection}

This is an empirical study which includes control groups where traditional methods are used and experimental groups where CLT method is used based on a comparison between these methods for a period of 6 months. It is mainly focused on the implementation of CLT in Albanian 9-year elementary schools in learning English as a foreign language through communication and interaction compared with other traditional methods used. The study analyzes the impact, results and advantages of the use in practice of CLT method in Albanian 9-year elementary schools on sixth, seventh, eighth and ninth grades, its efficacy in learning, in foreign language acquisition, students' performance in four language skills, students socialization and motivation, the role of teachers in the classroom and the relationship teacher-student and student-student. The data about the implementation of CLT method in practice are collected from teachers and students in Albanian 9-year elementary schools through classroom observation and tests. Classroom observations are focused on finding how the teacher develops the lessons and if it is based on CLT principles on experimental groups and how students react during the lesson in comparison with control groups. Observation gives the opportunity to study events and behaviors within their natural and specific context and is characterized by validity and it is structured in order to collect all the necessary data. It is done by the researcher which was not participant on the classroom activities but just listener and observer and it is done using a table based on questions to better record the data. Tests are used to measure students' acquisition and results on language learning in an effective way with real results and are used to compare students' results on learning based on their grades in both groups. They are based on evaluation of student's knowledge based on the material they have worked with during the period of research and are done at the end of the research period; they are designed and conducted by each participant teacher himself.

\section{Participants}

5 classes on the $6^{\text {th }}$ grade-134 participants -Age 11-12 years old

4 classes CLT method used -Experimental groups 
2 classes ALM/GTM method used-Control groups

4 classes on the $7^{\text {th }}$ grade-81 participants -Age 12-13 years old

1 class CLT method used -Experimental groups

3 classes ALM/GTM method used-Control groups

7 classes on the $8^{\text {th }}$ grade-136 participants -Age 13-14 years old

3 classes CLT method used -Experimental groups

4 classes ALM/GTM method used-Control groups

1 class on the $9^{\text {th }}$ grade-12 participants -Age $14-15$ years old

1 class CLT method used -Experimental groups

\section{CLT Techniques Used in Experimental Groups}

-Authentic Materials

Real communication and real context use of language in the classroom

-Scrambled Sentences

Logic, cohesion, coherence learnt

-Language Games

Free communication, free expression of ideas and opinions, motivation enhanced

-Strip Story

Socialization

-Role Play

Interaction

Through this techniques grammar and vocabulary was learned in context, in the classroom was created a social context, errors were not instantly and constantly corrected and teacher acted as a facilitator and counselor.

\section{ALM Techniques Used in Control Groups}

-Dialog Memorization

Specific context used

-Backward Build-up Drill

Model imitation

-Repetition Drill

Repetition

-Chain Drill

-Single and multiple slot Substation

-Transformation Drill

-Question-answer Drill

Given vocabulary, given grammar rules

Through these techniques there was no interaction and no socialization in the classroom, errors were instantly and constantly corrected, teacher acted as leader, controller.

\section{GTM Techniques Used in Control Groups}


-Translation of a Literary Passage

Specific context used, focused on translation

-Reading Comprehension Questions

Focused on reading and writing not on communication

-Antonyms/Synonyms/Cognates

Given vocabulary

-Deductive Application of Rules

Grammar rules are learnt deductively

-Fill in the Blank

Exercises to practice grammar rules

-Composition

Focuses on writing

Through these techniques there was no interaction and no socialization in the classroom, errors were instantly and constantly corrected, teacher acted as authority in the classroom.

\section{Results and Findings}

\section{Tests}

After implementing CLT method in experimental groups and ALM, GTM methods in control groups for a period of 6 months with the relevant techniques mentioned above. The tests were used to control student's knowledge and by referring to the tests' results we can make a comparison of the average grade of both involved groups. In the table below the mentioned participant classes above are placed numbered according to their participation in the relevant group and the initials added on each class refer to the participant school in order to be easily to identify them. They are placed on the table based on the class grade and based on the group to each they are compared to.

So, class $6^{1 \mathrm{NV}}$ was part of the experimental group compared with class $6^{2 \mathrm{NV}}$ which was part of the control group and we can see that there is a difference on the average grade of 1. 9. Class $6^{1 S G}$ was part of the experimental group compared with class $6^{2 S G}$ which was part of the control group and we can see that there is a difference on the average grade of 0.88 . Class $6^{\mathrm{MB}}$ was part of the experimental group compared with class $7 \mathrm{MB}$ which was part of the control group and we can see that there is a difference on the average grade of 0.47 . Class $6^{\mathrm{STH}}$ was part of the experimental group compared with class $7^{\mathrm{STH}}$ which was part of the control group and we can see that there is a difference on the average grade of 1.5 . Class $7^{1 \mathrm{NN}}$ was part of the experimental group compared with class $7^{2 \mathrm{NN}}$ which was part of the control group and we can see that there is a difference on the average grade of $\mathbf{0 . 2}$. Class $8^{1 \mathrm{NV}}$ was part of the experimental group compared with class $8^{2 \mathrm{NV}}$ which was part of the control group and we can see that there is a difference on the average grade of $\mathbf{0 . 5}$. Class $8^{1 \mathrm{SG}}$ was part of the experimental group compared with class ${ }^{25 G}$ which was part of the control group and we can see that there is a difference on the average grade of 1.43 . Class $8^{1 \mathrm{NN}}$ was part of the experimental group compared with class $8^{2 \mathrm{NN}}$ which was part of the control group and we can see that there is a difference on the average grade of 1.00 . Class $8^{\mathrm{MB}}$ was part of the experimental group compared with class $9^{\mathrm{MB}}$ which was part of the control group and we can see that there is a difference on the average grade of 0.25 .

Table 1. Tests results

\begin{tabular}{|l|l|l|}
\hline Class & CLT- Experimental groups & ALM/GTM-Control groups \\
\hline $6^{1 \mathrm{NV}}$ & 8.5 & \\
\hline $6^{2 \mathrm{NV}}$ & & 6.6 \\
\hline $6^{1 \mathrm{SG}}$ & 8.76 & \\
\hline $6^{2 \mathrm{SG}}$ & & 7.88 \\
\hline
\end{tabular}




\begin{tabular}{|l|l|l|}
\hline $6^{\mathrm{MB}}$ & 7.2 & \\
\hline $7^{\mathrm{MB}}$ & & 6.73 \\
\hline $6^{\mathrm{STH}}$ & 9.2 & \\
\hline $7^{\mathrm{STH}}$ & & 7.7 \\
\hline $7^{1 \mathrm{NN}}$ & 7.2 & \\
\hline $7^{2 \mathrm{NN}}$ & & 7 \\
\hline $8^{1 \mathrm{NV}}$ & 6.8 & \\
\hline $8^{2 \mathrm{NV}}$ & & 6.3 \\
\hline $8^{1 \mathrm{SG}}$ & 7.3 & \\
\hline $8^{2 \mathrm{SG}}$ & & 5.87 \\
\hline $8^{1 \mathrm{NN}}$ & 7.2 & \\
\hline $8^{2 \mathrm{NN}}$ & & 6.2 \\
\hline $8^{\mathrm{MB}}$ & 7.25 & \\
\hline $9^{\mathrm{MB}}$ & & 7 \\
\hline
\end{tabular}

\section{Chart 1. Tests results}

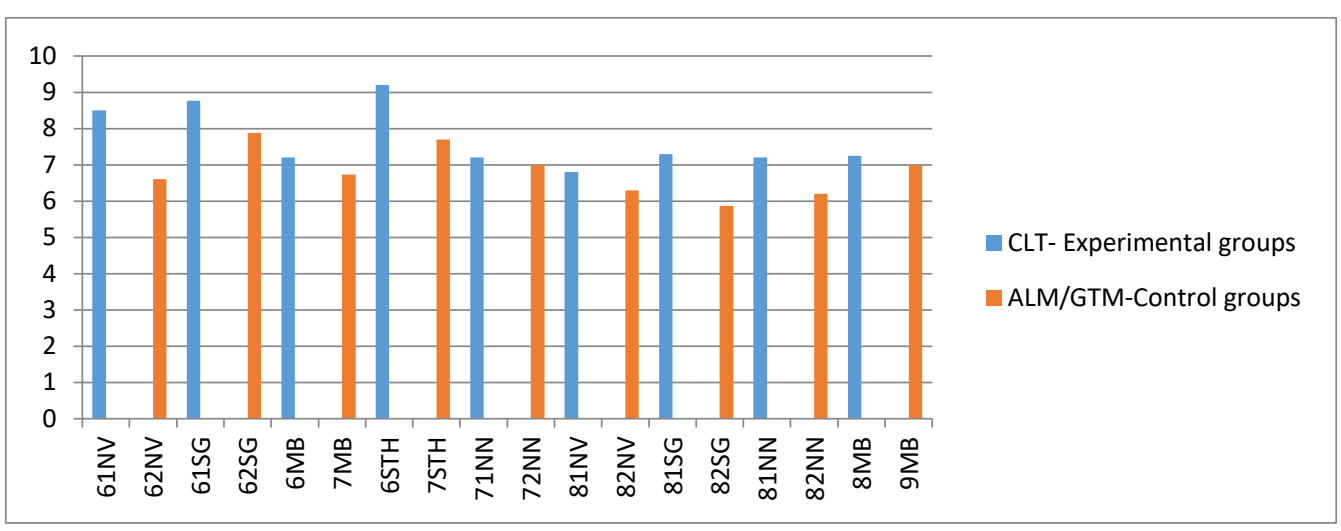

As we can clearly see on the table and chart below the average grade in the experimental groups compared with the relevant control groups is relatively higher. It can clearly be seen on the results above that there is a difference between experimental and control groups class participants in the average grade, in some of the classes the difference is bigger in some lower and not very much significant but in the overall it has differences and the overall difference of the average grade is 8.13 higher in experimental groups. This means that CLT usage has been more effective than the other methods and students learning and acquisition is better. Based on theoretical issues about the effectiveness of CLT method and positive issues of learning language in communication it is somehow evidence of theory proved in practice. Thornbury (1999) lists some advantages of the inductive way of learning a language and grammar: -When students self-discover grammar rules it is easier for them to acquire those rules by the existing mental structure than the other rules that are presented in a certain way to them. - In this way students can be more active during learning and not passive and this can bring them more motivation and attention. -And because collaboration is more effective in problem solving this give students the opportunity for more practice. While the deductive way of teaching grammatical rules may be frustrating for students and explanation is based on memorization. CLT that focuses mainly on communication and inductive learning of language and grammar can provide to the learner a better opportunity to communicate than a method based on grammatical rules, repetition and memorization. Students have the opportunity to create real communication and focus on their own learning and can build up their own communicative competence because even their errors are tolerated by the teacher, they can also develop fluency as well as accuracy and expand and develop all language skills. Richards (2006) 


\section{Classroom Observation}

During the implementation of these methods there were observation hours included in all the participant classes both experimental and control groups and the researcher kept notes on a designed table with questions that helped discover the frequency of principles implementation of CLT, ALM and GTM methods. For each question all the relevant information on the overall answers collected of all the tables and notes and all the results are shown on the table below. The table indicates the frequency in which each question takes an answer. Just to specify English is the target language while Albanian is the native language.

\section{Table 2. Classroom Observation Results}

\begin{tabular}{|l|l|l|l|l|l|l|}
\hline Observation Question & \multicolumn{2}{l|}{ Always } & \multicolumn{2}{l|}{ Sometimes } & \multicolumn{2}{l|}{ Rarely } \\
\hline Method & CLT & ALM/GTM & CLT & ALM/GTM & CLT & ALM/GTM \\
\hline $\begin{array}{l}\text { Does the teacher speak only English during the } \\
\text { lesson? }\end{array}$ & $\mathrm{X}$ & & & & & $\mathrm{X}$ \\
\hline $\begin{array}{l}\text { Do the students speak only English during the } \\
\text { lesson? }\end{array}$ & $\mathrm{X}$ & & & & & $\mathrm{X}$ \\
\hline $\begin{array}{l}\text { Teaching is focused more on grammar and } \\
\text { grammatical rules? }\end{array}$ & & $\mathrm{X}$ & & & $\mathrm{X}$ & \\
\hline $\begin{array}{l}\text { Teaching is focused more on functional use of } \\
\text { language and communication? }\end{array}$ & $\mathrm{X}$ & & & & & $\mathrm{X}$ \\
\hline The teacher focuses more on accuracy? & & $\mathrm{X}$ & & & $\mathrm{X}$ & \\
\hline The teacher focuses more on fluency? & $\mathrm{X}$ & & & & & $\mathrm{X}$ \\
\hline $\begin{array}{l}\text { The activities used in the classroom include real } \\
\text { communication? }\end{array}$ & $\mathrm{X}$ & & & & & $\mathrm{X}$ \\
\hline $\begin{array}{l}\text { Practice with authentic material is one of the } \\
\text { aims of the lesson? }\end{array}$ & $\mathrm{X}$ & & & & & $\mathrm{X}$ \\
\hline $\begin{array}{l}\text { Activities are mainly developed on group or pair } \\
\text { work? }\end{array}$ & $\mathrm{X}$ & & & $\mathrm{X}$ & & \\
\hline Teaching is student-centered? & $\mathrm{X}$ & & & & & $\mathrm{X}$ \\
\hline Teaching is teacher-centered? & & $\mathrm{X}$ & & & $\mathrm{X}$ & \\
\hline $\begin{array}{l}\text { The main aim of the lesson is Communicative } \\
\text { Competence? }\end{array}$ & $\mathrm{X}$ & & & & & $\mathrm{X}$ \\
\hline $\begin{array}{l}\text { Error correction is done constantly and } \\
\text { continuously? }\end{array}$ & & $\mathrm{X}$ & & & $\mathrm{X}$ & \\
\hline $\begin{array}{l}\text { The objective of the lesson is to give students } \\
\text { the opportunity to express their opinions and } \\
\text { develop their social and creative thinking skills? }\end{array}$ & $\mathrm{X}$ & & & $\mathrm{X}$ & & \\
\hline $\begin{array}{l}\text { The teacher creates opportunities for easier } \\
\text { communication student-student and teacher- } \\
\text { student? }\end{array}$ & $\mathrm{X}$ & & & $\mathrm{X}$ & & \\
\hline
\end{tabular}

During the lessons on experimental groups where CLT method principles were used the teacher spoke always only English in the classroom while on the control groups where ALM/GTM methods principles were used the teacher spoke rarely only English in the classroom which means that the teacher generally spoke English but also Albanian on the classroom and just rarely spoke only English and not Albanian at all. The same frequency in speaking was even for the students. In CLT teaching was always focused more on functional use of language and communication and rarely on grammar and grammatical rules while on ALMIGTM it was the contrary. In control groups which relatively include ALMIGTM principles the teacher was always more focused on accuracy and rarely on fluency and error correction was always done constantly and continuously while on experimental groups it was the entire contrary. Real communication, practice with authentic material and communicative competence were the main aims of CLT lesson, they were always included and teaching was always student-centered, these were rarely used on ALM/GTM and teaching was always teacher-centered. On CLT activities were always mainly developed on group or pair work, the objective of the lesson was to give students the opportunity to express their opinions and develop their social and creative thinking skills, and the teacher created opportunities for easier communication student-student and teacher-student, these activities happened only sometimes 
on ALM/GTM lesson.

Based on these results we can analyze the CLT impact on:

-Teaching and learning- the purpose of CLT was communication, free and real use of language and context and authentic materials. In ALM vocabulary and grammar was learned through imitation, memorization and repetition, in GTM grammar was learned through deductive rules, in both these methods there was lack of students' interaction and activities were directed by the teacher. The overall effectiveness of CLT usage can be seen on the average grade of the students' participants on the experimental classes.

-Motivation- Motivation helps students to study in the classroom, and is very important in learning a new foreign language. $\mathrm{CLT}$ is the method which gives importance to students' motivation through creating a warm climate in the classroom and through activities which enable students to freely communicate and express their ideas in a real context. In ALM and GTM students feelings were not taken into consideration.

-Socialization-There was a lot of interaction in CLT because of interactive techniques used, work in groups, games, role plays etc. In ALM and GTM there was lack of interaction and socialization because the techniques were based on exercises, repetition and memorization.

-Fluency-In CLT the teacher was focused on communication which directly affects fluency and created situations where real communication was used. In this way students learnt new vocabulary, language functions, and interactive strategies through communication even grammatical competence and rules were learnt inductively through using in in communication. In ALM and GTM little importance was given to communication, students where focused in a given context, the focus was in grammatical rules and vocabulary was learnt through memorization and repetition.

-Teacher and Student role-In CLT teacher acted as felicitator and counselor, teacher was not dominant and student was in the center and became aware about their own learning management. In ALM and GTM the teacher was a leader or authority in the classroom and controlled students' behavior and language learning, was a director and a model. Students became imitators and memorizer.

Through the above discussion it is shown that the more involved the student, the greater will be the result in learning. Interactive teaching methods such as CLT are very important in learning a foreign language because they make the students active and motivate them to learn more to achieve effective learning and learning in collaboration enhances students' social skill by improving knowledge and social skills, leadership ability of teachers and learning ability of students by increasing their enthusiasm and determination to succeed in learning, it improves interpersonal relationships, creates models of social behavior and engages students in the learning process and aims to improve critical thinking skills. These principles are really useful and effective and if they will be applied in the classroom the teachers need to modify their teaching methodology. In this way the activities that include repetition, memorization, grammatical rules, drills, and multiple choices should be replaced with activities that include communication, interaction, meaning negotiation, tasks and games. The shift to CLT should be viewed as a new strategy to implement contemporary methodology on foreign language teaching and developing teachers' teaching skills and creativity in the classroom including even topics of interest for the students, which will help them be more motivated to develop their own learning strategies and confidence. Jacobs and Farrel (2003) identify some crucial components which help this shift such as: -Focusing more and giving attention on the role of the students in the classroom activities rather than on the external stimuli of the environment. In this way the attention shifts from the teacher to the student and teaching and learning shifts from teacher-centered to student-centered. -More attention should be given to the socialization of students in community and society rather than acting as individuals not considering the social or individual differences. In this way school becomes a more inclusive institution and connects school environment with social context and outside world. - Focusing more on the meaning and functional use of language rather than structural forms. -Viewing learning as a life-long process rather than learning just for a specific time and context and just for the sake of examination.

\section{Conclusion}

Using a contemporary interactive student-center method as CLT in teaching affects the motivation of students to learn English by creating security based on cooperation and interaction with other students or with the teacher while in traditional methods feelings of students are not taken into consideration and socialization of students, they interacted more with each 
other due to different involving activities while in traditional methods was a lack of socialization and interaction in activities used. CLT affects accuracy and fluency of language and provide students with vocabulary, language structure and functions as well as strategies to successfully interact and all this happened through communication. Grammatical competence and rules were acquired through communication. In traditional methods students were given the option not to communicate freely but were limited within a given context, in a limited number of sentences, more attention was paid to the teaching of grammar rules and memorizing words and models used. The purpose of the techniques used in ALM and in GTM was to learn new vocabulary words, correct pronunciation of words, and the transformation of sentences and rules of grammar. All these were presented and practiced only in one dialogue or given text. So the students were limited only to act within that framework and context. There was a lot of imitation, memorization and very little interaction student-student. The purpose of the techniques used in CLT was effectiveness, impact and advantages in motivation and socialization of students, in fluency and communication in English, in the role of teachers in the classroom as well as techniques that most affect the acquisition of a foreign language. CLT helped the teacher to assess the accuracy and fluency, linguistic structures and vocabulary while students communicated. All this implementation was reflected on the tests results which show higher average grades on experimental groups. The findings in this study are limited to the setting, number and context of participants, but it contributes as scientific evidence in the Albanian context and it shows the need for other extended researches. This paper is just a part of the study which is still continuing to analyze other data and results that will be presented on other following papers.

\section{References}

Brumfit, C. J. (1984). Communicative Methodology in Language Teaching: the Roles of Fluency and Accuracy. Cambridge University Press.

Hymes, D. (1972). On communicative competence, In J. B. Pride \& J. Holmes (ed. ), Harmondsworth: Penguin.

Jacobs, G. \& Farrel, T. (2003). Understanding and Implementing the CLT Paradigm. RELC Journal.

Larsen-Freeman, D. (2000). Techniques and Principles in Language Teaching. Oxford: Oxford University Press.

Richards, J. (2006) Communicative Language Teaching Today. Cambridge: Cambridge University Press.

Richards, Jack and Theodore Rodgers. (1986). Approaches and Methods in Language Teaching. Cambridge: Cambridge University Press.

Richards, Jack C. ; Theodore S. Rodgers (2001). Approaches and Methods in Language Teaching. Cambridge UK: Cambridge University Press.

Thornbury, S. (1999) How to Teach Grammar. England: Longman. 